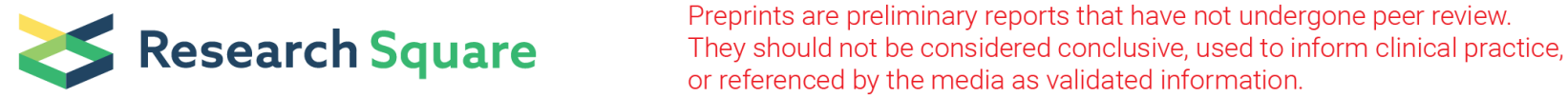

\section{In-Vivo Study of Green Synthesised Gold Nanoparticles on Inflammatory Cytokines as Diagnostic Biomarker in Acetaminophen Induced Immunotoxicity in Rat Model}

\section{Mousumi Mitra}

Raja Narendra Lal Khan Mahila Mahavidyalaya: Raja Narendra Lal Khan Women's College

\section{Sudeep Mitra}

Raja Narendra Lal Khan Mahila Mahavidyalaya: Raja Narendra Lal Khan Women's College

Dilip Kumar Nandi ( $\nabla$ dilipnandi2004@yahoo.co.in )

Raja Narendra Lal Khan Women's College https://orcid.org/0000-0003-0551-4505

\section{Nano Express}

Keywords: Acetaminophen, Terminaliaarjuna, immunotoxicity, gold nanoparticles

Posted Date: July 7th, 2021

DOl: https://doi.org/10.21203/rs.3.rs-629788/v1

License: (c) (i) This work is licensed under a Creative Commons Attribution 4.0 International License.

Read Full License 


\section{Abstract}

Nanomedicines are widely used as possible therapeutics and diagnostics for wide variety of diseases. It have been used for successful delivery of hydrophilic and hydrophobic small molecules drugs, and biomacromolecules, such as enzymes, recombinant proteins, peptides, hormones, monoclonal antibodies and also used for the delivery of nucleic acids of different sizes and structures.Gold nanoparticles possess promising ameliorative effects due to their distinctive properties such as high surface reactivity, biocompatibility, flexibility in functionalization and a broad range of delivery targets. This study was designed to investigate the protective effect of green synthesised gold nanoparticles (AuNPs) using aqueous bark extract of Terminaliaarjunaon acetaminophen induced immunotoxicityin the experimental rat model.Group1-Control group; Group 2- Acetaminophen administered intraperitoneally at concentration of $500 \mathrm{mg} / \mathrm{kg}$ of body weight for 14 days; Group 3- Co-administration of Terminaliaarjuna aqueous bark extract $(175 \mu \mathrm{g} / \mathrm{kg} /$ day $)$ along with acetaminophen $(500 \mathrm{mg} / \mathrm{kg} /$ day) treatment for 14 days; Group 4- Coadministration of AuNPs $(175 \mu \mathrm{g} / \mathrm{kg} / \mathrm{day})$ along with acetaminophen treatment $(500 \mathrm{mg} / \mathrm{kg} / \mathrm{day})$ intraperitoneally for 14 days. After 14 days all animals were sacrificed for the immunological analysis.Immunological analysis revealed that there was significant decrease in the IL-10 level with acetaminophen treatment but marked increase in the KIM-1, Cystatin C, TNF-alpha and, IL-18 level.After co-administration with AuNPs along with acetaminophen showed effective significant recovery in theexpression of inflammatory biomarkers. Hence, the results highlighted on the protective effectsAuNPs against acetaminophen inducedimmunotoxity.

\section{Introduction}

Nanomedicines are becoming prominent as possible therapeutics and diagnostics for wide variety of diseases, and have been also used in materials science applications, development of vaccine, engineering [1-2]. It have been used as a "depot" of various cargoes for successful delivery of hydrophilic and hydrophobic small molecules drugs, and biomacromolecules, such as enzymes, recombinant proteins, peptides, hormones, monoclonal antibodies and also used for the delivery of nucleic acids of different sizes and structures [3-4]. The large and fine structures of these nanoparticles can be tailored to assist specific therapeutics and to protect them against enzymatic or hydrolytic degradation, provide suitable surroundings for solubility and for gated drug release. Additionally they can be equipped with "smart" elements (peptides, proteins, antibodies, sugars, aptamers, etc.) for their effective delivery to the target organs, tissues and subcellular compartments [5].

Gold nanoparticlespossess promising ameliorative effects due to their distinctive properties such as high surface reactivity, biocompatibility, flexibility in functionalization and a broad range of delivery targets[68].It have been found to be beneficial for controlled release and delivery of various compounds including antibiotics [9], anticancer drug [10],antioxidants [11], glucose [12], and isotopes [13]. Many of the research is devoted to the investigation of synthesis, functionalization and stabilization of gold nanoparticles [14] The preparation methods are based on the reduction of gold ions, mostly as solutions of $\mathrm{HAuCl}_{4}$. It has been reported that the common stabilizing agents are sodium citrate, cetyltrimethyl ammonium bromide, 
transferrin, while common species used for functionalization include various oligonucleotides, amines, peptides, antibodies and lipids. To enhance the biocompatibility of gold nanoparticles it is preferable to use nontoxic agents [15]. Additionally gold nanoparticles synthesis needs a protecting agent, which can adsorb over the surface of the newly synthesised nanoparticles to prevent from additional growth and agglomeration. Hence, the size and shape of the nanoparticles can be controlled by utilizing appropriate reduction and agitation methods as well as synthesis conditions, ie, $\mathrm{pH}$, temperature, stirring and utilization of extrinsic fields(such as ultrasound). This contemplation resulted in several publications that proposed, green reduction and protection agents as new synthesis routes for gold nanoparticles synthesis [16-17]. Mostly plants [18], algae, fungi and bacteria were used as reducing and stabilizing agents [19]. Terminalia arjuna commonly known as arjuna, belongs to the family of Combretaceae. The bark extract of Terminalia arjuna contains various bioactive constituents such as triterpenoid, saponin, tannin, ellagic acid, gallic acid and proanthocyanidines [20]. In this study, gold nanoparticles were synthesised using the reducing property of Terminalia arjuna bark extract.

Acetaminophen ( $\mathrm{N}$-acetyl-p-aminophenol; APAP)is commonly and widely used analgesic and antipyretic over-the-counter drug. Use of acetaminophen in therapeutic concentrations is considered to be safe but can cause severe liver and kidney damage after an overdose, ultimately leading to hepatorenal failure [21-22]. More recent studies on the pathogenesis of acetaminophen induced acute liver failure revealed that not only liver injury, but also ensuing inflammatory response of the immune system which critically determine the severity and outcomes of the disease. Various non-parenchymal cells, chemokines, cytokines are included in the inflammatory response following acute liver injury. Beside this different lymphoid derived cells, kupffer cells, dendritic cells and infiltrating monocyte derived macrophage are involved in acute liver injury[23].

Nanoparticles can interact with different components of the immune system and either enhance or inhibit its function [24]. The potentiality of nanoparticles to persuade an immune response depends on the physiochemical properties (size, hydrophobicity, charge, etc.), surface targeting moieties, the route of administration, therapeutic pay load and the animal model. Cytokines are polypeptides produced by broad range of cells including immune cells in response to activation that regulate various biological process and acts as mediator of inflammation and immune responses. Nanoparticles can interact with proteins including antibodies, so it is frequently used to target specific cells and tissues, understanding the use of cytokines as biomarkers of undesirable immune stimulation associated with engineered nanomaterials emerging as a crucial component of nanoparticle safety testing.

The present study provides an indication on the systemic immunotoxicity caused by acetaminophen. Alterations in the expression of inflammatory biomarkers are key event of hepatorenal toxicity caused due to acute overdose of acetaminophen. This study emphasises on the ameliorative effects of green synthesised gold nanoparticles (AuNPs) by using Terminalia arjuna bark extract on acetaminophen induced immunotoxicity in the experimental rat model.

\section{Materials And Methods}


Green synthesis and characterization of gold nanoparticles using aqueous bark extract of Terminalia arjuna

Terminalia arjuna ([Roxb.]Wight \&Arn.) bark was collected from Laterite region of Gope Palace (Raja N.L Khan Women's College) Medinipur, Paschim Midnapore district, West Bengal, India. Taxonomic identification was done by Dr. Dulal Chandra Das, Associate Professor, Department of Botany, Raja Narendra Lal Khan Women's College (Autonomous)and the plant voucher number was given as RNLKWC/121/2016.

Green synthesis of gold nanoparticles were done by using aqueous bark extract of Terminalia arjuna and characterized as described by Mitra et al.[25] Hundred millilitre of $1 \mathrm{mM}$ chloroauric acid $\left(\mathrm{HAuCl}_{4}\right)$ solution was reduced by $10 \mathrm{~mL}$ of Terminalia arjuna aqueous bark extract and heated for 10 minutes at $60-70^{\circ} \mathrm{C}$ to yield a ruby red colored dispersion. This transformation in the colour from pale yellow to ruby red

indicated the formation of green synthesised gold nanoparticles (AuNPs) by using Terminalia arjuna bark extract.

\section{Experimental Animals}

To conduct the experimental studies twenty four (24) healthy Wistar strain male albino rats weighing 100 to $120 \mathrm{gm}$ were taken from authorized Chakraborty Animal suppliers, Kolkata (M/S Chakraborty Enterprise Registration no.: 1443/PO/b/11/CPCSEA). The rats were distributed into four equal groupsand werehoused in polypropylene cages. They were maintained under standard laboratory condition that includes $22 \pm 4^{\circ} \mathrm{C}, 12 \mathrm{hr}$ light/ dark cycle and $50 \pm 10 \%$ humidity with proper supplementation of standard food and water ad libitum. Animals were acclimated to this environmental condition for 14 days before treatment.

All animal experiments were performed as per the Animal Ethical Committee guidelines of Raja Narendra Lal Khan Women's College (Reference number: 14/ IAEC (05) / RNLKWC / 2019 and were maintained as per Committee for the Purpose of Control and Supervision of Experiments on Animal (CPCSEA), Government of India (Registration no. : 1905 / PO / Re / S / 2016/ CPCSEA).All experimental protocols have been approved by the Constitutional of Institutional Animals Ethics Committee (IAEC) of Raja NarendraLal Khan Women's College (Autonomous), Midnapore-721102, West Bengal, under registered CPCSEA.

\section{Experimental Design}

Experimental animalswere divided into four groups (6 rats in each group). Group1- Control group; Group 2-Acetaminophen administered intraperitoneally at concentration of $500 \mathrm{mg} / \mathrm{kg}$ of body weight for 14 days; Group 3- Co-administration of Terminalia arjuna aqueous bark extract ( $175 \mu \mathrm{g} / \mathrm{kg} / \mathrm{day})$ along with acetaminophen $(500 \mathrm{mg} / \mathrm{kg} /$ day) treatment for 14 days; Group 4- Co-administration of 

days.

\section{Sacrifice Of Animals And Collection Of Blood And Tissue}

After a period of 14 days treatment all animals were sacrificed then blood samples and liver as well as kidney tissue were collected. The collected tissue was perfused with PBS and then stored at $-20^{\circ} \mathrm{C}$ in sterile container for preparation of tissue homogenates.

Separation of serum and homogenization of liver and kidney tissue

Blood sample was allowed to clot for two hours at room temperature and then centrifuged for 15 minutes at approximately $1000 \mathrm{xg}$ at $4^{0} \mathrm{C}$.

For the preparation of tissue homogenates, tissues are rinsed in ice cold PBS to remove excess blood thoroughly and weighed before homogenization. The tissues were minced to small pieces homogenized them in $5-10 \mathrm{~mL}$ of PBS with a glass homogenizer on ice. The resulting suspension was sonicated at $4^{0} \mathrm{C}$ to further break the cell membranes. After that, homogenates are centrifuged for 5 minutes at $5000 \times \mathrm{g}$ at $4^{0} \mathrm{C}$. The resulting supernatant was collected and assayed immediately.

\section{Measurement Of Kidney Injury Molecule (Kim-1)}

KIM-1 was identified from the serum of different experimental group animalsusing a sandwich ELaISA kit(DL- Develop; Wuxi Donglin Sci\& Tech Development Co., Ltd.). The assay was performed as per the instructions mentioned in the kits.

\section{Measurement Of Cystatin-c (Cst C)}

Quantitative measurement of CST C in rat serum and kidney tissue homogenates were done by using sandwich ELISA kit (DL- Develop; Wuxi Donglin Sci \& Tech Development Co., Ltd.).

\section{Measurement Of Cytokines By Sandwich Elisa}

The level of pro-inflammatory (TNF- alpha, IL-18) and anti-inflammatory (IL-10) cytokines in the serum and tissue homogenates of different experimental groups was measured using a sandwich ELISA kit(DLDevelop; Wuxi Donglin Sci\& Tech Development Co., Ltd.). The assay was performed as per the instructions mentioned in the kits.

\section{Statistical Analysis}


The data were calculated and statistical analysis was done by using statistical package, Origin 6.1 Northampton, Mass, USA. The statistically collected data was calculated and were expressed as Mean \pm $\mathrm{SE}, \mathrm{n}=6$. Comparison was done between the means of control and with all experimental groups, by ANOVA followed by multiple two tail t- test. Bars for a specific data differ from each other significantly ( $p$ $<0.05)$.

\section{Results}

\section{Kidney Injury molecule (KIM-1)expression}

There was significant increase $(p<0.05)$ in KIM-1 expressionin serum after 14 days administration with acetaminophen at concentration of $500 \mathrm{mg} / \mathrm{kg}$; body weight in group 2 rats,compared to the control group(group 1). The expression of KIM-1 significantly reduced $(p<0.05)$ after co-administration of AuNPs $(175 \mu \mathrm{g} / \mathrm{kg} /$ day $)$ along with acetaminophen treatment in group 4 , compared to Terminalia arjuna coadministered group 3 rats (Fig. 1A).

\section{Cystatin C(Cst C) Expression}

Administration of acetaminophen (500 $\mathrm{mg} / \mathrm{kg}$; body weight) after 14 days of intoxication resulted a significant elevation $(p<0.05)$ of Cystatin $C$ expression in serum and kidney tissue homogenate in acetaminophen treated group, in comparison with the normal control group. On co-administration of AuNPs at the dose $175 \mu \mathrm{g} / \mathrm{kg}$; body weight for 14 days the level of Cystatin $C$ in serum and kidney tissue significantly reduced $(p<0.05)$ in group 4 rats, in comparison to Terminalia arjuna and acetaminophen treated groups (Fig. 1B, 1C).

\section{Immunological Markers}

\section{Pro-inflammatory biomarkers}

Activities of the pro-inflammatory cytokines like TNF- alpha and IL-18 had been observed in the serum as well as liver and kidney tissue homogenates. There was marked significant increase $(p<0.05)$ in the activity of TNF- alpha and IL-18 after acetaminophen intoxication, in comparison to the control group. AuNPs $(175 \mu \mathrm{g} / \mathrm{kg} /$ day $)$ co-administration along with acetaminophen significantly decreased $(p<0.05)$ the concentration of pro-inflammatory cytokines to their near normal value compared to Terminalia arjuna and acetaminophen treated groups (Fig. 2A, 2B,2C,2D)

\section{Anti-inflammatory Biomarkers}


Alterations in the concentrations of anti-inflammatory cytokine (IL-10) were measured in the serum as well as liver and kidney tissue homogenates of different experimental groups. The level of IL-10 in serum as well as liver and kidney tissue homogenates had been significantly decreased $(p<0.05)$ in acetaminophen administered group 2 rats, compared to the control group. In addition, co-administration of AuNPs at an effective dose of $175 \mu \mathrm{g} / \mathrm{kg} /$ day along with acetaminophen in group 4 rats significantly elevated $(p<0.05)$ the level of IL-10, in comparison to Terminalia arjuna treated group3 rats and acetaminophen treated group 2 rats (Fig. 3A, 3B,3C).

\section{Discussion}

Acetaminophen (APAP) is widely usedas pain reliever and fever reducer agent. After consumption, APAP is taken up from the intestine and small fraction (5-10\%) gets metabolized in hepatocytes by cytochrome P450 isoforms into the alkylating metabolite N-acetyl-p-benzoquinone imine (NAPQI). Hepatocytes are protected by glutathione (GSH) that binds with NAPQI and convert it into a harmless reduced form hence, preventing their covalent binding to liver proteins [26]. But due to an overdose of APAP, GSH level is depleted, increasing the amount of NAPQI whichcovalently binds to mitochondrial proteins, forming cytotoxic protein adducts [27]. The formation of protein adducts in hepatocytes leads to oxidative stress, with increased reactive oxygen species (ROS) production. ROS supress the transcription factor NF-KB and trigger autophosphorylation and activate c-Jun N-terminal kinase (JNK) [28]. Further, the activated JNK increases the ROS production leading to mitochondrial membrane permeabilization and dysfunction [29]. This leads to hepatocyte necrosis, followed by release of various danger-associated molecular patterns (DAMPs) mainly heat-shock protein-70 (HSP-70), high-mobility group box protein 1 (HMGB-1), and DNA fragments [30]. Generally, kuffer cells (KC) and dendritic cells (DC) recognizes DAMPs molecules, via toll like receptors, subsequently leading to the activation of these cell types [31].In macrophages, a cytosolic multiprotein complex , inflammasome is formed that helps to generate inflammatory response. After inflammasome formation IL-18 and IL-1 $\beta$ are secreted by $\mathrm{KC}$, thereby further triggering the innate immune system, leading to the recruitment of immune cells at the site of inflammation and advancing hepatocyte necrosis [23]. Another alternative mechanism that leads to hepatocyte necrosis, is the presentation of NAPQI-protein adduct peptides by the human leukocyte antigen (HLA) on antigen presenting cells (APCs), leads to the activation of helper $T$ (Th) cells and ultimately to the cytotoxic T cells (Tc). Tc express surface FasL and release TNF-a, perforin and granzyme and are responsible for activation of death pathways in sensitized hepatocytes, thereby inducing necrosis [32].

The second target organ of acetaminophen toxicity is kidney and renal dysfunction that occurs among patients with marked hepatic damage. Hepatorenal disorder remains as one of the serious health problems. However there are no such satisfactory protective drugs for the treatment of serious hepatorenal disorders. For later time points in severe cases, where inflammatory responses are more relevant, the only curative treatment option is kidney and liver transplantation [33] with a survival rate of about $70 \%$ for first years. Considering the high cost and lack of potential donors for this treatment, so there is an urgent need for alternative treatment options. As herbal drugs play an effective role in the 
management of liver and kidney disorders, which helps to speed up the natural healing process without any side effects. Therefore, in this study green synthesised gold nanoparticles (AuNPs) by using bark extract of Terminalia arjuna is used as an early asymptomatic diagnostic biomarker for acetaminophen induced immunotoxicity. AuNPs might serve as an operative platform for effective drug delivery by virtue of its ability to carry and deliver drug to disease site and to determine the alternative harmless therapy against liver and kidney dysfunctions.

Cytokines are group of proteins secreted by cells of immune system and plays an important role in cell signalling. They are important to health and disease, specifically in host response to infections and help to regulate immune response. Cytokines including interleukins [34],interferons [35], tumor necrosis factor, colony-stimulating factors, and several growth factors act as potential biomarkers of hepatic and renal toxicity. Generally, these biomarkers help to determine the early damage to health caused by exposure to exogenous toxic substances, and provide an insight into the mechanism of the onset of these toxicants to adversely affect certain individuals or groups [36].

KIM-1 is a type I transmembrane glycoprotein and one of the gene families that form T-cell immunoglobulin mucin (Tim). KIM-1 is considered as a sensitive biomarker for nephrotoxicity [37].After administration of acetaminophen in group 2 rats the KIM-1 level gets significantly elevated $(p<0.05)$, in comparison to the control group. This marked elevation in the KIM-1 expression is mainly due to the exposure of toxic substance to the kidney which might cause proximal tubular injury as well as nephrotoxicity. However, on co-administration of AuNPs at an effective dose of $175 \mu \mathrm{g} / \mathrm{kg} / \mathrm{day}$ along with acetaminophen treatment significantly reduced $(p<0.05)$ the expression of KIM-1 in serum, compared to Terminalia arjuna and acetaminophen treated groups. This marked decrease might be due to the potential beneficial effect of AuNPs which can protect from acetaminophen induced nephrotoxicity.

Cystatin C (CST C) or cystatin 3 is a 13-kDa protein formerly known as interalia $y$-trace, post- $\gamma$ globulin and it is considered one of the extracellular inhibitors of cysteine proteases. CST C is encoded by CST3 gene, is mainly used as biomarker of kidney function. CST C level in serum and kidney tissue homogenate significantly increases $(p<0.05)$ in acetaminophen treated groups, in comparison to control. After acetaminophen intoxication, CST C level rises mainly due to the decline in kidney function as well as decline in the glomerular filtration rate, thereby signaling a state of 'preclinical' kidney dysfunction. In AuNPs co-administered group, CST C level significantly decreases $(p<0.05)$, in comparison to Terminalia arjuna and acetaminophen treated groups. The decline in the CST $\mathrm{C}$ level emphasises, that AuNPs treatment helps in proper functioning of the kidney without any renal disorder.

Pro-inflammatory cytokines are the signaling molecule secreted by the immune cells like helper T cells, macrophages and other cell types that promote inflammation. It has been reported by several researchers, that in case of severe hepatotoxicity pro-inflammatory cytokines such as interleukin 12 (IL-12), tumor necrosis factor-alpha, interleukin 6 (IL-6) rises with reduced anti-inflammatory cytokines like interleukin 10 (IL-10), and transforming growth factor- beta [38]. During in-vivo toxicity, pro-inflammatory cytokines activates macrophages and promotes cell mediated immune responses and tissue damage [39]. In this 
experimental study, there was marked significant increase in pro-inflammatory cytokines (TNF- alpha and IL-18) and decrease in anti-inflammatory response(IL-10) associated with acetaminophen intoxication.

This kind of alterations in the immunological responses was recovered to their normal value by coadministration of AuNPs. Hence, green synthesised gold nanoparticles (AuNPs) by using Terminalia arjuna helped to ameliorate acetaminophen induced immunotoxicity in rat model.

\section{Conclusion}

To conclude, the findings suggest that AuNPs exerted its hepato- nephroprotective effects in experimental animals by acting as an anti-inflammatory agent. Hence, AuNPS might serve as an effective diagnostic biomarker for acetaminophen induced immunotoxicity.

\section{Declarations}

\section{Ethics approval and consent to participate}

Animal Ethics approval was maintained as per the Animal Ethical Committee guidelines of Raja NarendraLal Khan Women's College (Reference number: 14/ IAEC (05) / RNLKWC /2019) and were maintained as per Committee for the Purpose of Control and Supervision of Experiments on Animal (CPCSEA), Government of India (Registration no.:1905/PO/Re/S/2016/CPCSEA).

\section{Consent for publication}

Not applicable as the manuscript work is original.

\section{Competing Interests}

The authors declare that they have no competing interest.

\section{Funding}

There is no such involvement of any funding sources for the publication of this manuscript.

\section{Authors Contributions}

MM had contributed in definition of intellectual content, literature search, data acquisition, data analysis, manuscript preparation and manuscript editing. SM had contributed in manuscript editing; DKN had contributed in concept, design, manuscript editing and statistical analysis. All authors have read and approved the manuscript for submission.

\section{Acknowledgement}

The authors are very much thankful to Department of Science and Technology (DST), Government of West Bengal for providing the technical support (Vide Sanction No.: 308 (Sanc.)/ST/P/S\&T/1G-74/2017)for conduction of the work.

\section{References}

1. Nystrom AM, Wooley KL. The importance of chemistry in creating well-defined nanoscopic embedded therapeutics: devices capable of the dual functions of imaging and therapy. Acc. Chem. Res. 2011; 44:969-978. [PubMed: 21675721]

2. Von Maltzahn G, Park JH, Lin KY, Singh N, Schwoppe C, Mesters R, Berdel WE, Ruoslahti E, Sailor MJ, Bhatia SN. Nanoparticles that communicate in vivo to amplify tumour targeting. Nat. Mater. 2011; 10:545-552. [PubMed: 21685903] 
3.Davis ME, Zuckerman JE, Choi CH, Seligson D, Tolcher A, Alabi CA, Yen Y, Heidel JD, Ribas A. Evidence of RNAi in humans from systemically administered siRNA via targeted nanoparticles. Nature.2010; 464:1067-1070. [PubMed: 20305636]

4. Zhang K, Fang H, Shen G, Taylor JS, Wooley KL. Well-defined cationic shell crosslinked nanoparticles for efficient delivery of DNA or peptide nucleic acids. Proc. Am. Thorac. Soc. 2009; 6:450-457. [PubMed: 19687218]

5. Elsabahy, M.; Dufresne, MH.;Leroux, JC. In Materials for Nanomedicine.Torchilin, V.; Amiji, M., editors. Hackensack: Pan Stanford Publishing; 2010. p. 169-234.

6.B.Panchapakesan, B. Book-Newell, P. Sethu, M. Rao, and J. Irudayaraj,“Goldnanoprobesfortheranostics,”Nanomedicine, vol.6,pp.1787-1811,2011.

7. D.Pissuwan, T. Niidome, and M. B. Cortie,"The forthcoming applications of gold nanoparticles in drug and gene delivery systems,"JournalofControlledRelease,vol.149,no.1,pp.65-71, 2011.

8. A. S. Thakor, J. Jokerst, C. Zavaleta, T. F. Massoud, and S. S. Gambhir, "Gold nanoparticles: a revival in precious metal administrationtopatients,"NanoLetters,vol.11,pp.4029-4036, 2011.

9. R. T. Tom, V. Surayanarayanan, P.G. Reddy, S.Baskaran andT.Pradeep,"Ciprofloxacinprotectedgoldnanoparticles,"Langmuir,vol.20,no.5,pp.1909-1914,2004

10. G. E. Craig, S. D. Brown, D. A. Lamprou, D. Graham, and N. J. Wheate, "Cisplatin-tethered gold nanoparticles that exhibit enhanced reproducibility, drug loading, and stability: a step closer to pharmaceutical approval?" Inorganic Chemistry, vol. 51,pp.3490-3497,2012.

11. C. A. Simpson, J. Salleng K, D. E. Cliffel, and D. L. Feldheim, "Invivotoxicity,biodistribution, andclearanceofglutathionecoated gold nanoparticles," Nanomedicine, vol. 9, pp. 257-263, 2013.

12.K. Song, P. Xu, Y. Meng et al., "Smart gold nanoparticles enhance killing effect on cancer cells," International Journal of Oncology,vol.42,no.2,pp.597-608,2012.

13. S. Guerrero, J. R. Herance, S. Rojas et al., "Synthesis and in vivoevaluationofthebiodistributionofa18Flabeledconjugate gold-nanoparticle-peptide with potential biomedical application,"BioconjugateChemistry,vol.23,pp.399-408,2012.

14.Giljohann DA, Seferos DS, Daniel WL, Massich MD, Patel PC, Mirkin CA. Gold nanoparticles for biology and medicine. AngewChemlnt Ed Engl. 2010;49(19):3280-3294.

15.Ghosh P, Han G, De M, Kim CK, Rotello VM. Gold nanoparticles in delivery applications. Ad Drug Deliv Rev. 2008;60(11):1307-1315. 
16. Salam HA, Rajiv P, Kamaraj M, Jagadeeswaran P, Gunalan S, Sivaraj R. Plants: green route for nanoparticle synthesis. Int Res J Biol Sci. 2012; 1(5):85-90.

17. Shukla D, Vankar PS. Synthesis of plant parts mediated gold nanoparticles. Int J Green Nanotechnol. 2012;4(3):277-288.

18.Mittal AK, Chisti Y, Banerjee UC. Synthesis of metallic nanoparticles using plant extracts. Biotechnol Adv. 2013;31(2):346-356.

19.Das SK, Marsili E. A green chemical approach for the synthesis of gold nanoparticles: characterization and mechanistic aspect. Rev Environ SciBiotechnol. 2010;9(3):199-204.

20.ChathaSAS ,Hussain Al, Asad R, et al.(2014) Bioactive components and antioxidant properties of Terminaliaarjuna L. extracts. J Food Process Technol 5:1-5.

21. Nelson SD. Mechanisms of the formation and disposition of reactive metabolites that can cause acute liver injury. Drug Metab Rev 1995; 27:147- 77.

22. Trumper L, Monasterolo LA, and Elias MM. Probenecid protects against in vitro acetaminophen induced nephrotoxicity in male Wistar rats. J PharmacolExpTherapeat1 998; 283: 606-10.

23.Jaeschke $H$, Williams CD, Ramachandran $A$, et al. Acetaminophen hepatotoxicity and repair: the role of sterile inflammation and innate immunity. Liver Int 2012;32:8-20.

24.Zolnik BS, Gonzalez-Fernandez A, Sadrieh N, Dobrovolskaia MA. Nanoparticles and the immune system.Endocrinology.2010; 151:458-465.

25.Mitra M, Bandyopadhyay A, Gouriprasad D, Nandi DK.Protective Role of Green Synthesized Gold Nanoparticles using TerminaliaarjunaagainstAcetaminophen Induced Hematological Alterations in Male Wistar Rats.J Nanomed Nanotechnol.2019;10, doi:10.4172/2157-7439. 1000530.

26. Tirmenstein MA, Nelson SP. Sub cellular binding and effects on calcium homeostasis produced by acetaminophen and a non-hepatotoxic regioisomer3-hydroxyacetanilide in mouse liver. J BiolChem 1989; 264: 9814-9819.

27.Vermeulen NPE, Bessems JGM, Van DE, Straat R. Molecular aspects of paracetamol-induced hepatotoxicity and its mechanism based prevention. Drug Metab Rev 1992; 24: 367-407.

28. Hanawa N, Shinohara M, Saberi B, et al. Role of JNK translocation to mitochondria leading to inhibition of mitochondria bioenergetics in acetaminophen-induced liver injury. J BiolChem 2008;283:13565-77.

29.Chambers JW, LoGrasso PV. Mitochondrial c-Jun N-terminal kinase (JNK) signaling initiates physiological changes resulting in amplification of reactive oxygen species generation. J BiolChem 
2011;286:16052-62.

30. Dahlin DC, Miwa GT, Lu AY, et al. N-acetyl-pbenzoquinone imine: a cytochrome P-450-mediated oxidation product of acetaminophen. ProcNatlAcadSci U S A 1984;81:1327-31.

31. Martin-Murphy BV, Holt MP, Ju C. The role of damage associated molecular pattern molecules in acetaminophen-induced liver injury in mice. ToxicolLett 2010;192:387-94.

32. Han D, Shinohara M, Ybanez MD, et al. Signal transduction pathways involved in drug-induced liver injury. HandbExpPharmacol 2010:267-310.

33.Larsen FS, Wendon J. Understanding paracetamolinduced liver failure. Intensive Care Med 2014;40:888-90.

34.Horii, Y., Iwano, M., Hirata, E., Shiiki, M., Fujii, Y., Dohi, K. and Ishikawa, H. (1993) Role of interleukin-6 in the progression of mesangial proliferative glomerulonephritis. Kidney Int. 39(Suppl), S71-75.

35. Baron, S., Tyring, S. K., Fleischmann, W. R. Jr., Coppenhaver, D. H., Niesel, D. W., Klimpel, G. R., Stanton, G. J. and Hughes, T. K. (1991) The interferons. Mechanisms of action and clinical applications. JAMA $266,1375-1383$.

36.Finn, W. and Porter, G. (2003) Urinary biomarkers and nephrotoxicity. Clinical Nephrotoxins (2nd ed), pp. 621-655. Kluwer Academic Publishers, Massachusetts.

37. Ichimura, T., Bonventre, J. V., Bailly, V., Wei, H., Hession, C. A., Cate, R. L. and Sanicola, M. (1998) Kidney injury molecule-1 (KIM-1), a putative epithelial cell adhesion molecule containing a novel immunoglobulin domain, is up-regulated in renal cells after injury. J. Biol. Chem. 273, 4135-4142.

38.Shaw PJ, Hopfensperger MJ, Ganey PE, Roth RA. Lipopolysaccharide and trovafloxacincoexposure in mice causes idiosyncrasy-like liver injury dependent on tumor necrosis factoralpha. Toxicological Sciences. 2007 Aug 19;100(1):259-66.

39.Dinarello CA. Proinflammatory cytokines.Chest. 2000 Aug 1;118(2):503-8.

\section{Figures}



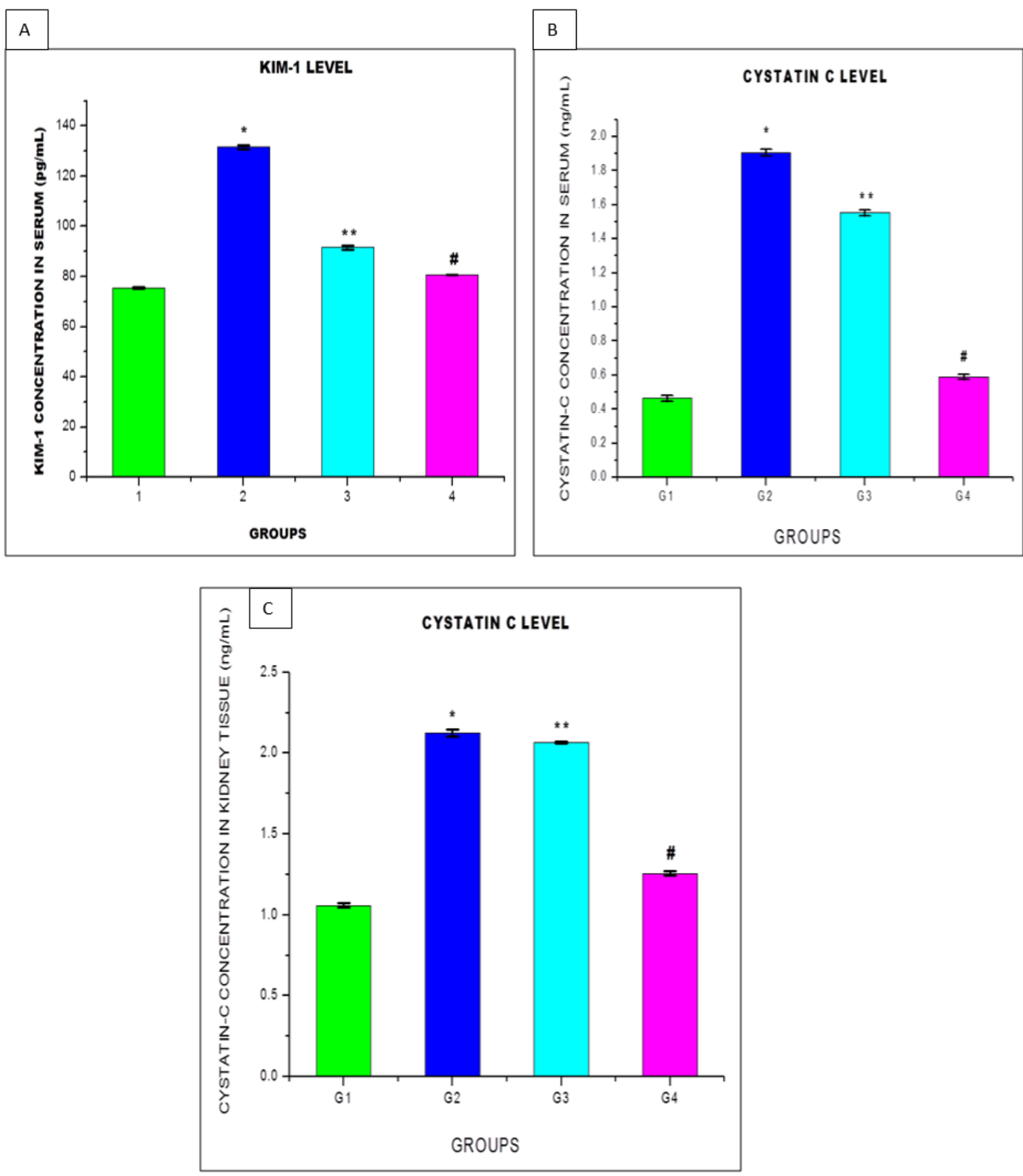

\section{Figure 1}

Graphical representation of A) KIM-1 level, B) Cystatin C level in serum, and C)Cystatin C level in kidney tissue homogenates of rats on different experimental groups. Data are expressed as Mean \pm SE $(n=6)$.ANOVA followed by multiple two-tail t-test and data with different superscripts $(*, * *, \#)$ in a specific vertical column indicates significant difference $(p<0.05)$ compared to control group.Groups, 
Group 1: Control, Group 2: Acetaminophen (500mg/kg/day) treated, Group 3: Terminaliaarjuna(175 $\mu \mathrm{g} / \mathrm{kg} /$ day $)+$ Acetaminophen, Group 4: AuNPs $(175 \mu \mathrm{g} / \mathrm{kg} /$ day $)+$ Acetaminophen
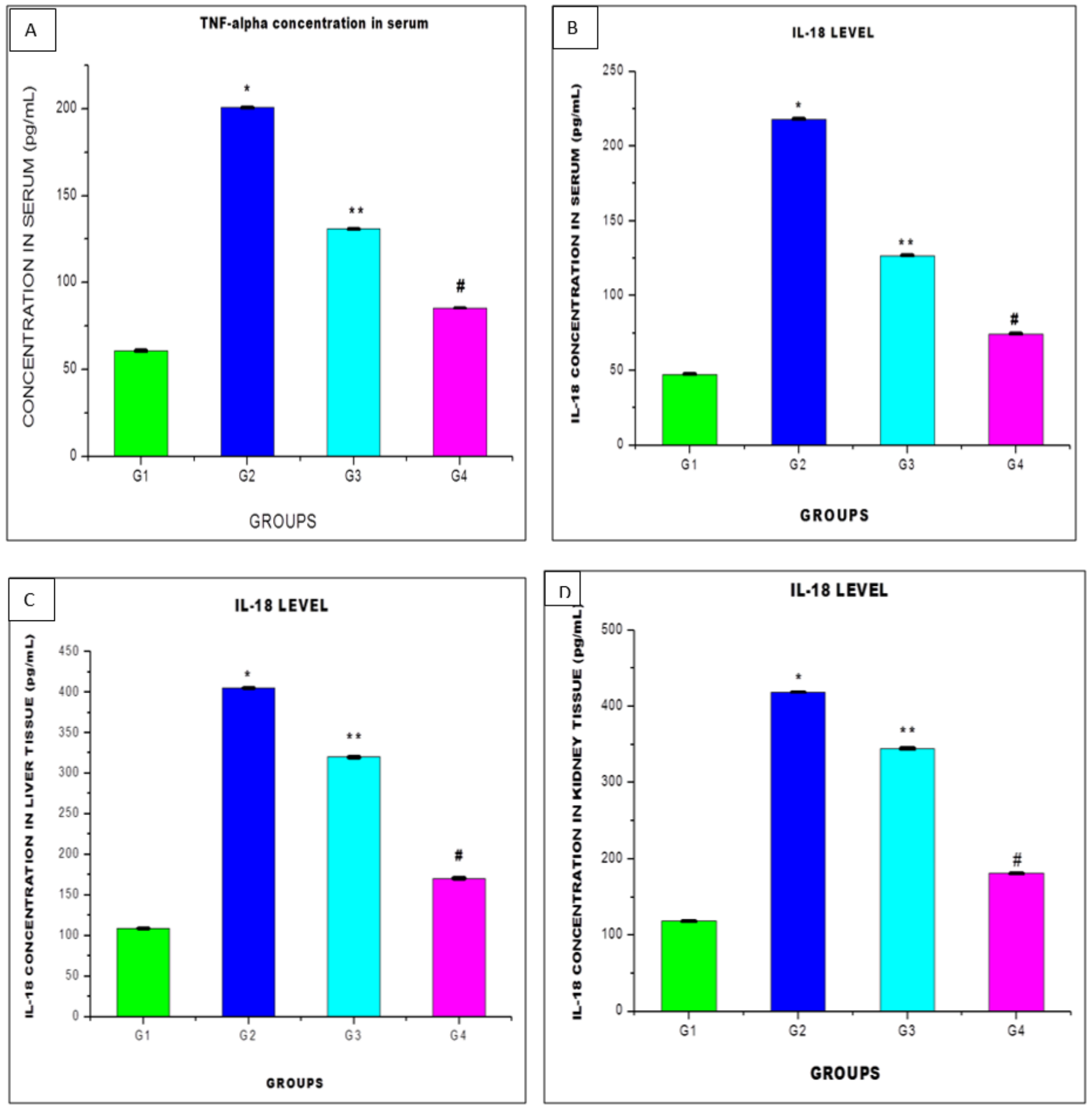

Figure 2

Graphical representation of pro-inflammatory cytokine A) TNF-alpha level, B) IL-18 level in serum, C) IL-18 level in liver tissueand, D) IL-18 level in kidney tissue homogenates of rats on different experimental groups. Data are expressed as Mean $\pm S E(n=6)$.ANOVA followed by multiple two-tail t-test and data with different superscripts $(*, * *, \#)$ in a specific vertical column indicates significant difference $(p<0.05)$ 
compared to control group. Groups, Group 1: Control, Group 2: Acetaminophen ( $500 \mathrm{mg} / \mathrm{kg} / \mathrm{day})$ treated, Group 3: Terminaliaarjuna(175 $\mu \mathrm{g} / \mathrm{kg} /$ day $)+$ Acetaminophen, Group 4: AuNPs $(175 \mu \mathrm{g} / \mathrm{kg} /$ day $)+$ Acetaminophen.
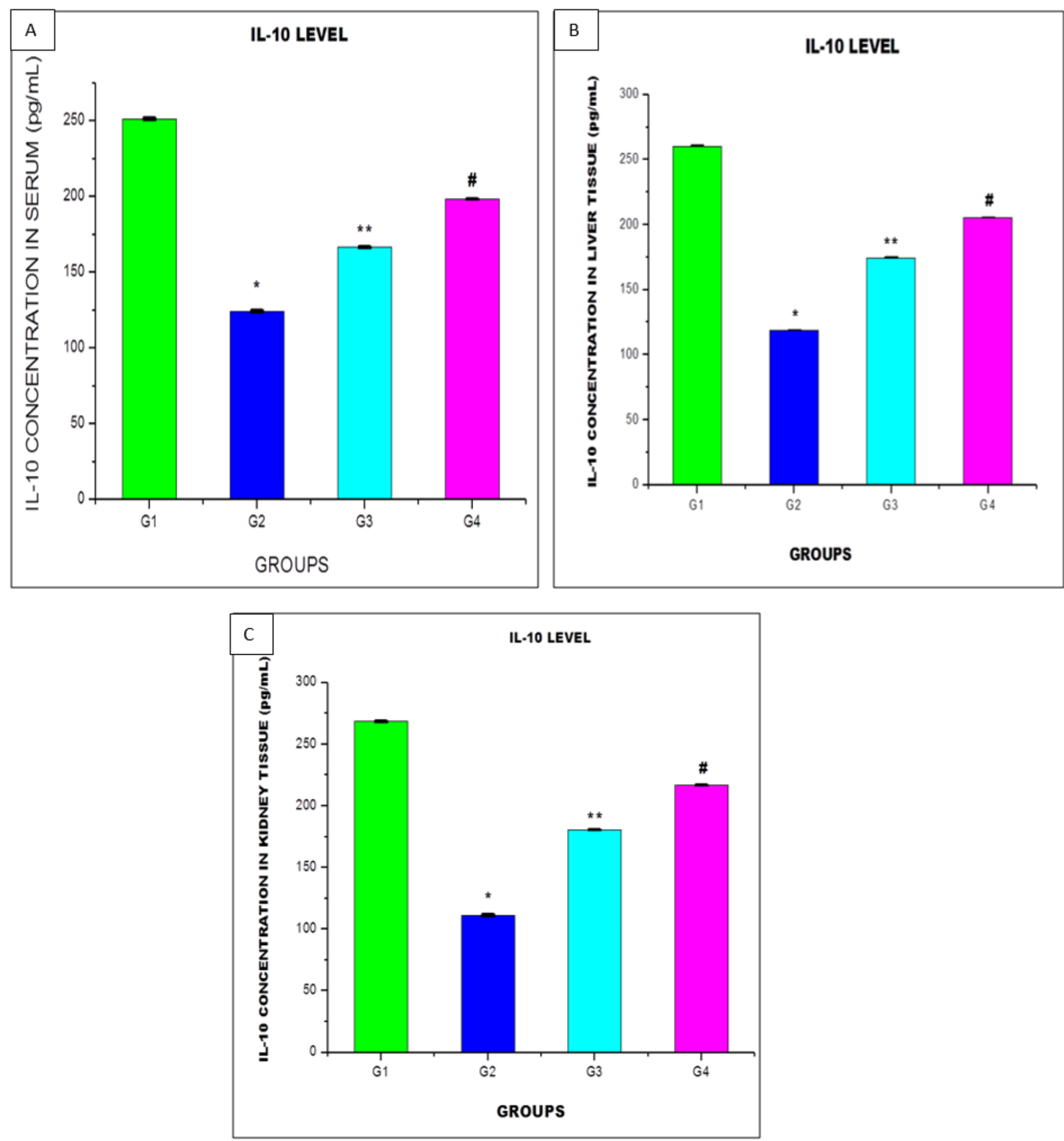

Figure 3

Graphical representation of anti-inflammatory cytokine A) IL-10 level in serum, B) IL-10 level in liver tissue and, C) IL-10 level in kidney tissue homogenates of rats on different experimental groups. Data are 
expressed as Mean \pm SE $(n=6)$.ANOVA followed by multiple two-tail t-test and data with different superscripts $(*, *, \#)$ in a specific vertical column indicates significant difference $(p<0.05)$ compared to control group. Groups, Group 1: Control, Group 2: Acetaminophen $(500 \mathrm{mg} / \mathrm{kg} /$ day) treated, Group 3: Terminalia arjuna $(175 \mu \mathrm{g} / \mathrm{kg} /$ day $)+$ Acetaminophen, Group 4: AuNPs $(175 \mu \mathrm{g} / \mathrm{kg} /$ day $)+$ Acetaminophen . 